\title{
HistÓRIA, UTOPIA E CONTRANARRATIVA DA NAÇÃO EM ANGELS IN AMERICA
}

\author{
Isabella Santos Mundim \\ Unileste/MG
}

\begin{abstract}
RES U M O
Este artigo visa analisar Angels in America, a Gay Fantasia on National Themes, do dramaturgo norte-americano Tony Kushner. Kushner, neste que é seu trabalho de maior impacto, retoma eventos e figuras da história recente de seu país, com foco na crise que a epidemia de AIDS desencadeia, o descaso do governo Reagan em relação às minorias que a epidemia vitima e a consequente devastação que acomete a comunidade gay da época. Nessa perspectiva, o trabalho de Kushner supera o mero registro e aponta para acontecimentos e pessoas ausentes do relato dominante. Para além da versão oficial, emerge aí uma contranarrativa da nação, comprometida com a construção de uma memória dos Estados Unidos a partir do viés da margem e da exclusão.
\end{abstract}

\section{PALAVRAS-CHAVE}

Tony Kushner, dramaturgia norte-americana contemporânea, contranarrativa da nação

Eu acredito que os excluídos são os detentores da verdade numa dada sociedade. Quem está à margem sabe coisas que o privilegiado não consegue apreender. (...) As pessoas que escrevem a história são aquelas que laboram e sofrem; são aquelas que lançam um olhar diferenciado sobre o mundo por conta de sua condição. Os despossuídos. ${ }^{1}$

Tony Kushner

\section{I}

Formulação da linguagem, a história corresponderia, em sua gênese, à representação da experiência e do acontecido, à narrativa que tenta dar conta da vida dos indivíduos e das comunidades. Nesse primeiro momento, portanto, a história desempenha uma função semelhante à da literatura, e "ambas podem ser associadas a

\footnotetext{
${ }^{1}$ Kushner. Citado por SHEWEY. Tony Kushner's Sexy Ethics. "I do believe the oppressed hold the truth in the society. The slave knows what the master can't know. (...) The people who are really making history are those tilling the soil of time and who understand how it works from a molecular, chemical point of view. That's the people at the bottom."
} 
um esforço para subjugar o caos," para edificar modelos "capazes de assegurar aos homens tanto a orientação como a verdade". ${ }^{2}$ Pode-se verificar a crise dessa concepção da história durante a primeira metade do século XIX: em 1830, Leopold Ranke, inspirado pelo ideário positivista, afirma que a tarefa do historiador consiste em mostrar, imparcial e objetivamente, como algo aconteceu, reduz-se a registrar a realidade observável. ${ }^{3}$

$\mathrm{Na}$ contemporaneidade, entretanto, essa crença na isenção e veracidade da escrita dos fatos não mais se sustenta. No último século, uma série de movimentos filosóficos e literários se dedicam a repensar os conceitos ligados ao estudo da historiografia, tais como memória, representação e verdade. O repensar esses conceitos desencadeia a produção das mais variadas formulações críticas sobre a (re)construção do passado. Essa produção teórica, por sua vez, traz outras - importantes - mudanças; mudanças em relação à recepção dos textos que inscrevem a versão oficial, bem como em relação ao sentido mesmo desses textos.

Nesse contexto de redefinição epistemológica no campo do saber histórico, o historiador e o escritor se aproximam, e aquele que registra os fatos pode se revelar um narrador, um inventor de verdades. ${ }^{4}$ Pois quem narra a história é um sujeito social, uma pessoa vinculada a espaço e temporalidade específicas, e um leitor parcial da realidade. Dessa maneira, o historiador que relata a experiência vai além da mera descrição factual, adota um foco narrativo e opta por revelar o caráter de fabricação de seu discurso. Ele recria o passado por meio da escrita. Ele, enfim, transforma o passado ao dar-lhe vida no presente - ao dar-lhe vida por meio do exercício da "memória imaginada".

Logo, em tempos pós-modernos, o discurso da história e o discurso da literatura passam a residir em fronteiras muito próximas, e o texto ficcional pode obter, nessa proximidade, alguma vantagem. Embora sem a autoridade outorgada ao historiador, o escritor de ficção pode tratar de aspectos que estão ausentes no discurso histórico, criando uma narrativa, por exemplo, que tem por protagonista um membro de minoria silenciada ou, ainda, escrevendo uma trama que resgata um episódio antes condenado ao ostracismo, atribuindo-lhe status e legitimidade. ${ }^{5}$ E assim procede o premiado dramaturgo Tony Kushner, quando decide lembrar o que a América esqueceu e estabelecer um diálogo com o passado.

Autor ousado, com Angels in America, a Gay Fantasia on National Themes, ele realiza uma vivência estética de uma experiência catastrófica, enquanto converte os cacos e as ruínas da história recente em teatro. O resultado desse empreendimento é uma gramática provocadora, que encoraja a experimentação com a linguagem e a forma e desafia as convenções do drama tradicional. É uma gramática, ainda, que ambiciona instaurar mudanças, que insiste na criação de uma relação dialética entre a arte e a política e enfatiza a narratividade da nação em detrimento de um registro pretensamente fiel da realidade. A insistência de Kushner em dar vida ao passado, a sua consciência

\footnotetext{
${ }^{2}$ SINDER. A reinvenção do passado e a articulação de sentidos: o novo romance histórico, p. 254.

${ }^{3}$ CARR. Que é história, p. 2-19.

${ }^{4}$ BURKE. Abertura: a nova história, seu passado e seu futuro, p. 7-37.

${ }^{5}$ HUTCHEON. Poética do pós-modernismo: história, teoria, ficção, p. 141-162.
} 
da incompletude do presente, a sua esperança em divisar o futuro a partir da memória, tudo isso compõe o seu texto dramático. Texto "histórico" invadido pela ficcionalização - texto de registro atravessado pela imaginação e reflexão e, enquanto tal, texto híbrido, suscetível de infinitas abordagens.

O cenário: Nova York. A época: novembro de 1985. Angels in America: Millennium approaches ${ }^{6}$ a primeira parte da narrativa épica de Kushner, tem início: esta é a história de dois homens diagnosticados com o vírus da AIDS; é, também, a história de dois casais cujos relacionamentos chegam ao fim, em meio a recriminações e mágoa. Prior Walter foi infectado; seu amante Louis Ironson, temeroso do sofrimento que está por vir, o abandona quando ele é internado. Joe e Harper Pitt são mórmons; enfrentam o fracasso do casamento de alguns anos, com Joe a procurar conforto em companhias masculinas e Harper a se refugiar em visões causadas por valium. Ainda: o segundo homem que se descobre doente é Roy M. Cohn, figura histórica, "pessoa real" cujos pensamentos e sentimentos o dramaturgo imagina. ${ }^{?}$

$\mathrm{Na}$ peça, esses personagens tão diversos ora se agrupam em pares, ora se separam: Louis e Roy são judeus, obcecados pela história e pelo destino da nação norte-americana. Louis e Joe envolvem-se sexualmente, traindo a confiança das pessoas que dizem amar. Roy e Prior sofrem de sintomas decorrentes da infecção pelo HIV. Louis e Harper perdemse em especulações sobre desastres globais na eventualidade de uma crise pessoal. Prior e Harper alucinam. Harper é visitada pelo Sr. Lies, um membro da Ordem Internacional dos Agentes de Viagem (IOTA) que promete salvá-la de seu cotidiano infeliz e levá-la para a Antártica. Prior torna-se um profeta e atende, com relutância, ao chamado de um anjo que irrompe através do teto de seu quarto.

A uni-los, o compartilhamento de um fardo, qual seja, o fardo da nacionalidade. Eles são "filhos de Reagan", habitantes de um Estados Unidos intolerante, cujos traços distintivos são o culto ao conservadorismo religioso e político e um sistema socioeconômico que perpetua as desigualdades. Os cortes nas despesas sociais, a redução de impostos concedida aos especuladores, a concessão de favores a grupos de interesses especiais, o aumento dos gastos militares são o índice do ressurgimento republicano, sinalizam o repúdio a um projeto liberal e uma inversão de prioridades. Em todo o país, os consumidores da classe média e da elite vão às compras, e o norte-americano médio aplaude a administração e expressa entusiasmo. ${ }^{8}$ Não surpreende, pois, que aqueles

\footnotetext{
${ }^{6}$ KUSHNER. Angels in America, a Gay Fantasia on National Themes, p. 1-125.

${ }^{7}$ Em notas que acompanham a peça, Tony Kushner explica o processo de reconstrução dessa personalidade infame: "for the most part the acts attributed to the character Roy, such as his illegal conferences with Judge Kaufmann during the trial of Ethel Rosenberg, are to be found in the historical record. But this Roy is a work of dramatic fiction; his words are my invention, and liberties have been taken." In: KUSHNER. Angels in America, a Gay Fantasia on National Themes, p. 11.

${ }^{8}$ BREEN. A era Reagan, p. 717-740.
} 
que ousam insurgir-se contra o governante popular tenham encontrado dificuldade. Apontar falhas, disputar a versão oficial, sugerir mudanças, tudo isso constitui tarefa árdua. A história homogeneizante e disciplinadora se mantém, com o poder institucionalizado fazendo frente à oposição e subsumindo críticas e questionamentos na unidade discursiva de sua narrativa legitimadora do Estado.

A esta narrativa excludente contrapõem-se as falas de alguns personagens. Entre eles, destaca-se Harper. Ao contrário de muitos compatriotas seus, ela não se deixa seduzir por promessas de grandiosidade vindoura. A jovem, que vez por outra ocupa o "limiar da revelação", vê além, sabe da "catástrofe" que se avizinha: "Ao redor do mundo tudo entra em colapso, mentiras vêm à tona, sistemas de defesa revelam-se obsoletos." 9 Decadência e ruína, ela admite, são metáforas apropriadas à era em que vive. Nela, a sociedade se desintegra, os corpos tornam-se morada de um vírus mortal, a camada de ozônio depaupera. O que vem a seguir, provavelmente, não é paz nem prosperidade.

Nessa mesma perspectiva inscreve-se Belize, amigo próximo de Prior e enfermeiro de Roy Cohn. Tal qual Harper, ele resiste ao apelo para tomar parte na fantasia de um futuro maravilhoso. O presente lhe impede de sonhar. Negro e gay, Belize sabe que não tem lugar nesse Estados Unidos que teme quem é diferente e condena a permissividade. O projeto nacional dos políticos e intelectuais republicanos criara uma nação atrofiada, a serviço daqueles e apenas daqueles que se identificavam com a imagem do consenso social. O sentimento de pertencimento, o sentido de história são elementos legitimadores de uma pátria de poucos, que lhes é impossível amar.

Eu odeio a América. (...) Eu odeio este país. Nada além de grandes idéias, e histórias, e gente morrendo, e pessoas [preconceituosas]. Quem compôs o hino nacional sabia o que fazia. Ele fez "liberdade" soar tão aguda, que ninguém a alcança. Isso foi premeditado. Nada no mundo soa menos como liberdade. Vá ao quarto 1013 do hospital e eu lhe mostrarei a América. Terminal, maluco e cruel. ${ }^{10}$

Os depoimentos de Harper e Belize são percorridos por um fio comum de ultraje e desilusão. Para eles, o "sonho americano" é algo fugidio, que está sempre a lhes escapar. Daí a crítica - recorrente - às premissas básicas da ideologia norte-americana. O hino, símbolo nacional importante, sofre ataque, e o mito (fundador) da extensão progressiva da liberdade para números sempre crescentes de pessoas é veementemente contestado. Ademais, o texto sugere que é Roy Cohn, um paciente terminal e ocupante do quarto 1.013 no hospital em que Belize trabalha, quem incorpora a América, uma referência, por si só, bastante acusatória.

Descrito como "o centro da maldade humana" ${ }^{11}$ Cohn é uma criatura enraivecida, um homem acostumado a fazer valer a sua vontade. Assistente do Senador Joseph

\footnotetext{
${ }^{9}$ KUSHNER. Angels in America, a Gay Fantasia on National Themes, p. 23.

${ }^{10}$ KUSHNER. Angels in America, a Gay Fantasia on National Themes, p. 228. "I hate America. (...) I hate this country. It's just big ideas, and stories, and people dying, and [prejudiced] people like you. The white cracker who wrote the national anthem knew what he was doing. He set the word 'free' to a note so high nobody can reach it. That was deliberate. Nothing on earth sounds less like freedom to me. You come with me to room 1013 over at the hospital, I'll show you America. Terminal, crazy and mean." ${ }^{11}$ KUSHNER. Angels in America, a Gay Fantasia on National Themes, p. 227. "the polestar of human evil".
} 
McCarthy e correligionário de diversas administrações presidenciais republicanas, ele foi advogado de acusação no julgamento que condenou Ethel Rosenberg à morte. As provas, à época, não eram conclusivas. Além disso, durante o processo, os códigos de ética foram violados. Irregularidades à parte, a execução da suposta espiã russa na cadeira elétrica é um motivo de orgulho profundo do lobista reacionário. Seu temperamento explosivo e autoritário, sua vitalidade intensa, suas opiniões ofensivas, tudo isso é recriado por Kushner a partir de registros (sempre) incompletos e causa um grande efeito dramático. Um exemplo: quando seu médico lhe informa que as lesões que traz na pele são manifestação do vírus da AIDS, Cohn não aceita o diagnóstico. Ele não contraíra a "praga gay" e se encarregaria de dar fim à carreira de qualquer profissional de medicina que o refutasse.

Diga: "Roy Cohn, você é homossexual." E eu vou me dedicar a destruir sistematicamente sua reputação, seu trabalho e sua carreira no estado de Nova York, Henry. Eu sou capaz disso. (...) Seu problema, Henry, é que você se apega demais às palavras, aos rótulos, tanto que você acredita que eles são o que parecem. AIDS. Homossexual. Gay. Lésbica. Você acha que nomes indicam com quem alguém se deita? Pois não indicam. (...) Como todos os rótulos, eles só indicam uma coisa: o lugar que um indivíduo ocupa na cadeia alimentar. $\mathrm{Na}$ hierarquia. Eles indicam poder; não ideologia ou opção sexual. Não se trata de quem compartilha minha cama, mas de quem atende meu telefonema, de quem me deve favores. É a isso que um rótulo se refere. Para aqueles que não me entendem, eu sou um homossexual porque durmo com homens. Mas eles se enganam. Homossexuais não são homens que dormem com outros homens. Homossexuais são homens que, após quinze anos de tentativa, não conseguem passar uma lei antidiscriminação na Câmara Municipal. Homossexuais são homens que não conhecem ninguém e que ninguém conhece. Que não têm poder. Eu pareço ser isto, Henry? ${ }^{12}$

O argumento do qual Roy Cohn se vale denota a estagnação intelectual, moral e espiritual que acomete os Estados Unidos. Pessoa influente, político conservador, ele "não é homossexual". Ele "é um heterossexual... que dorme com homens". Ele tampouco sofre de AIDS, pois "AIDS acomete homossexuais". ${ }^{13}$ Essa sua negação da homossexualidade e da doença, a recusa em admitir que diferença e poder, marginalidade e respeito sejam conciliáveis representam assim a hipocrisia e a homofobia correntes no país e refletem o silêncio da presidência de Ronald Reagan durante sete anos de epidemia.

\footnotetext{
${ }^{12}$ KUSHNER. Angels in America, a Gay Fantasia on National Themes, p. 50-51. "Say: 'Roy Cohn, you are a homosexual. And I will proceed, systematically, to destroy your reputation and your practice and your career in New York State, Henry. Which you know I can do. (...) Your problem, Henry, is that you are hung up on words, on labels, that you believe they mean what they seem to mean. AIDS. Homosexual. Gay. Lesbian. You think these are names that tell you who someone sleeps with, but they don't tell you that. (...) Like all labels they tell you one thing and one thing only: where does an individual so identified fit in the food chain, in the pecking order? Not ideology, or sexual taste, but something much simpler: clout. Not who I fuck or who fucks me, but who will pick up the phone when I call, who own me favors. This is what a label refers to. Now to someone who does not understand this, homosexual is what I am because I have sex with men. But really this is wrong. Homosexuals are not men who sleep with other men. Homosexuals are men who in fifteen years of trying cannot get an antidiscrimination bill through City Council. Homosexuals are men who know nobody and who nobody knows. Who have zero clout. Does this sound like me, Henry?"
}

${ }^{13}$ KUSHNER. Angels in America, a Gay Fantasia on National Themes, p. 52. 
Durante a campanha que o elegeu, Reagan anuncia, entre outros temas, a recuperação dos valores familiares e a defesa do modo de vida americano. Seu discurso assegura-lhe o apoio de grupos fundamentalistas religiosos, cuja influência se fará sentir quando é chegada a hora de definirem diretrizes para as políticas públicas. Esta "nova direita" que ascende ao poder mostra-se relutante, desde o princípio, em enfrentar a síndrome misteriosa que ataca as comunidades gays, os usuários de drogas intravenosas e os imigrantes haitianos. A teoria da retribuição divina é popular entre os membros da administração, com o porta-voz da Maioria Moral, Jerry Falwell, afirmando que "AIDS é a ira de Deus recaindo sobre os homossexuais" e o presidente da nação sugerindo que a doença é a punição justa daqueles que praticam sexo ilícito. ${ }^{14}$

O descaso é evidente. Não se investe em pesquisa. Funcionários do alto escalão interferem nas deliberações do Congresso e impedem a alocação de recursos para programas de conscientização e para melhoria nos tratamentos. C. Everett Koop, responsável pela pasta da saúde, é obrigado a promover a agenda conservadora em vez de se dedicar à circulação de informações que pudessem evitar mais contaminações. Milhares de pessoas haviam morrido e tantas outras se contaminado quando o presidente Reagan pronuncia-se a respeito da doença pela primeira vez, na III Conferência Internacional sobre AIDS. Nas palavras de um respeitado biógrafo do presidente:

A resposta do governo Reagan à epidemia foi ineficaz e irresponsável... Em 1981, 199 casos de contaminação pelo vírus haviam sido reportados. Oito anos depois, mais de 55.000 pessoas haviam morrido de AIDS, um número que excede o total de perdas na campanha militar no Vietnã ou na Guerra da Coréia. ${ }^{15}$

Além disso, a elite, animada por uma vocação civilizatória e por uma missão moralizante, recorre a uma retórica simplista que lê a doença como ameaça ao corpo político. ${ }^{16}$ A AIDS é uma força invasora e, como tal, justifica a implementação de medidas, não importa quão preconceituosas sejam, desde que essas assegurem o policiamento das fronteiras da nação. A hostilidade contra os doentes é a regra e discutese, nos corredores do poder, a possibilidade da criação de colônias de internamento bem como a organização de um registro nacional para pessoas contaminadas, nos moldes daquele que armazena os dados de criminosos. ${ }^{17} \mathrm{O}$ governo lidera pelo exemplo e a população, em sua maioria, discrimina, ofende, culpa. No decorrer de dois mandatos republicanos, a tradição e a família são preservadas, às custas da agonia e morte de uma geração inteira de homossexuais.

Desse modo, os personagens de Kushner, com o espírito e o corpo alquebrados, falam por aqueles que travam batalha contra a AIDS e por aqueles que pereceram, enquanto denunciam a indiferença criminosa do Estado. Sobreviventes, cada um deles, de uma tragédia pública e pessoal, eles trazem na enunciação, no pesar e na revolta as cicatrizes da experiência. Contaminados, estigmatizados, visionários, eles se manifestam

\footnotetext{
${ }^{14}$ SHILTS. O prazer com risco de vida, p. 154-178.

${ }^{15}$ CANNON, Lou. Citado por SHILTS. O prazer com risco de vida, p. 201.

${ }^{16}$ SONTAG. AIDS and its Metaphors, p. 89-183.

${ }^{17}$ SHILTS. O prazer com risco de vida, p. 179-204.
} 
e as suas vozes, múltiplas, são a matéria-prima para o texto dramático. Coragem e covardia, espontaneidade e artifício, ultraje e tristeza, ódio e esperança, incredulidade e vergonha formam um coro dissonante, um mosaico representativo da diversidade de discursos, que ecoam, contradizem ou declaram independência.

Logo, Angels in America supera o mero registro. Excede-o, retirando dos incidentes não apenas os mecanismos sociais e políticos que impulsionam a crise, mas a complexidade mesma de uma gente que se defronta, a cada dia, com o desafio de viver e morrer em um Estados Unidos que abomina a doença e o fracasso. Para além da versão oficial e do relato dominante, emerge essa contranarrativa que reescreve a nação de Reagan, trazendo à tona um lado ainda não vislumbrado. A peça de Kushner, então, é mais uma tentativa de "saber de quem é a história que sobrevive" ou "de quem é a verdade que se conta", ${ }^{18}$ mais uma experiência estética comprometida com a construção de memória e passado norte-americanos a partir da perspectiva das pessoas excluídas dos mitos nacionais, a partir da perspectiva da margem.

\section{III}

No desfecho de Angels in America: Millennium Approaches, ${ }^{19}$ Prior é surpreendido pela chegada de um anjo, a manifestação física da bela voz que há um tempo lhe visitava. A preparação é finda e o trabalho do doente/visionário está prestes a começar, "Saudações, Profeta; A Grande Obra principia; O Mensageiro chegou." ${ }^{20}$ A interação que se segue toma a forma de flashbacks, quando um Prior, que está perdendo a visão, torna Belize seu confidente e compartilha a mensagem.

Em peça que tem por título uma expressão - Perestroika - que designa mudanças políticas e sociais significativas no cenário internacional, o enviado divino profere um evangelho de inércia, de estagnação. É imperativo, diz ele, que toda a criação cesse de andar, de migrar, de desejar. A mobilidade promíscua do ser humano, a sua vontade de ser diferente do que era, o seu impulso criativo são atributos por demais sedutores, e Deus, ao que parece, cai vítima desses encantos em 1906, ocasião em que deixa o paraíso para não mais retornar.

O progresso, aqui, implica destruição, já que o abandono celestial deixa-nos, a todos, à mercê do caos que ameaça dominar a existência, desamparados. As guerras, os desastres ecológicos, a própria epidemia constituem o resultado desse ir em frente constante, do potencial para mudança que caracterizam a humanidade. As entidades que substituem Deus como guardiões da vida no mundo, no entanto, conservam a esperança de que Ele regresse caso o homem pare e interrompa o seu caminhar.

Os anjos de Kushner, que descem aos Estados Unidos, são assim reminiscentes de uma concepção teórica e teológica anterior. Eles evocam a já famosa imagem do anjo da

${ }^{18}$ HUTCHEON. Poética do pós-modernismo: história, teoria, ficção, p. 159-162.

${ }^{19}$ KUSHNER. Angels in America, a Gay Fantasia on National Themes, p. 119-125.

${ }^{20}$ KUSHNER. Angels in America, a Gay Fantasia on National Themes, p. 125. "Greetings, Prophet; The Great Work begins; The Messenger has arrived." 
história, de Walter Benjamin, desenvolvida em seu texto "Sobre o conceito da história". 21 Esse anjo da história que Benjamin imagina não consegue mover-se livremente, por conta da tempestade que sopra do paraíso. Impelido para o futuro de maneira inexorável, o anjo, de asas aprisionadas e impotentes, mantém seu olhar fixo no passado, seu rosto voltado para os escombros que se acumulam, sua postura a sugerir, talvez, o desejo de retorno, de reparar o que se perdeu. A tempestade, Benjamin afirma, "é o que chamamos progresso", ${ }^{22}$ e o amontoado de debris corresponde às ruínas e catástrofes da história.

Tal qual o anjo da história, o "anjo da América" parece lamentar as tragédias que se abatem sobre os homens, e anseia ser capaz de restaurar o mundo a um estado ideal ou, na impossibilidade deste projeto, ser capaz de impedir o advento de outros cataclismas, de novas pragas. Para tanto, o visitante angelical presenteia a humanidade, na figura de Prior, com o "tomo da imobilidade", que faz parar o tempo e interrompe o progresso, tanto da história quanto da doença que vive nos corpos contaminados. A oferta aceita, Prior juntar-se-ia aos anjos no céu, lá permanecendo por quanto dure o universo, livre das limitações da carne. A nostalgia por um paraíso perdido, todavia, não o fascina: Prior decide recusar a graça que lhe é concedida, argumentando,

nós não podemos simplesmente parar. Nós não somos rochas - o progresso, a migração, o movimento (...) constituem modernidade. Algo nos anima; todos os seres vivos agem dessa maneira. Nós desejamos. Mesmo que só desejemos imobilidade, ainda assim, desejamos. Mesmo que estejamos avançando mais rápido do que devíamos. Nós não podemos esperar. (...) Eu quero mais vida. Eu não consigo evitar. Eu quero. Tenho enfrentado situações terríveis, e há outros que experimentam sofrimento muito maior, mas... Eles continuam vivendo. Quando são mais espírito do que corpo, mais feridas do que pele, quando ardem em agonia, quando moscas desovam nos olhos de seus filhos, eles vivem. A morte costuma dar cabo da vida. Eu não sei se é o animal em mim. Eu não sei se morrer exige mais coragem. Mas eu reconheço o hábito. O vício de estar vivo. Nós vivemos na ausência de esperança (...) Isso é tão insuficiente, tão inadequado mas... Mesmo assim, abençoem-me. Eu quero mais vida. ${ }^{23}$

Prior, ao pedir mais vida, ao insistir na mudança, rebela-se contra a inércia celeste. Progresso, para ele, configura-se êxtase doloroso, amadurecimento pessoal. Além das ruínas da história, da sofisticação tecnológica, das teorias evolucionistas, ele consegue vislumbrar um futuro de dificuldades e esperança, de sofrimento e solidariedade. Um futuro que, afinal, tem início no presente, quando figuras diversas se reúnem ao redor do leito de morte de Roy Cohn para abençoá-lo. Belize, o enfermeiro que testemunha

\footnotetext{
${ }^{21}$ BENJAMIM. Sobre o conceito da história, p. 222-232.

${ }^{22}$ BENJAMIM. Sobre o conceito da história, p. 226.

${ }^{23}$ KUSHNER. Angels in America, a Gay Fantasia on National Themes, p. 263-267. "We can't just stop. We're not rocks - progress, migration, motion is... modernity. It's animate, it's what living things do. We desire. Even if all we desire is stillness, it's still desire for. Even if we go faster than we should. We can't wait. (...) I want more life. I can't help myself. I do. I've lived through such terrible times, and there are people who live through much worse, but... You see them living anyway. When they're more spirit than body, more sores than skin, when they're burned and in agony, when flies lay eggs in the corners of the eyes of their children, they live. Death usually has to take life away. I don't know if that's just the animal. I don't know if it's not braver to die. But I recognize the habit. The addiction to being alive. We live past hope. (...) It's so much not enough, so inadequate but... Bless me anyway. I want more life."
} 
seu fim, está presente. Louis, judeu liberal, que não sente senão raiva e desprezo por Cohn, é quem diz a prece, quem recita o Kadish. Nessa tarefa, ele recebe a ajuda do fantasma de Ethel Rosenberg, que também comparece e despede-se daquele que foi seu algoz.

O encontro de vivos e mortos, homens e mulher, heterossexual e gays, negro e brancos, agnóstico e judeus, sinaliza uma utopia que pode vir a se concretizar. O perdão, tanto quanto o progresso, é a base sobre a qual uma comunidade inclusiva será erigida. Saber perdoar, escolher fazê-lo mesmo em face à ofensa e crueldade é uma prática redentora, e a generosidade de quem perdoa o resgata, a ele e a quem é perdoado, do pesadelo da história oficial.

Em vida, Roy Cohn afirma uma identidade que não é a sua. A doença, ironicamente, o conecta à comunidade gay, com sua agonia fornecendo uma prova incontestável da homossexualidade que negara. Ele é um deles, mais uma entre milhares de vítimas, sacrificado, como tantos, ao descaso estatal. Importante notar que seus crimes não são esquecidos, apesar de perdoados: "Filho da mãe", ${ }^{24}$ acrescentam Louis e Ethel, ao concluírem a oração do Kadish. Por fim, ele é aceito a despeito de sua covardia, sua intolerância, sua tirania. Nada mais adequado, já que a integração será, esta sim, a regra, marca de um Estados Unidos que se converte em espaço de inclusão, de negociação de diferenças e identidades.

A nação que Kushner imagina incorpora "novos 'povos' em relação ao corpo político", gera "outros locais de significação", produz "arenas não nomeadas". ${ }^{25}$ Sua narrativa dramática multiplica fronteiras, com um epílogo que celebra, novamente, a representação liminar. A família ideal(izada) não corresponde, aqui, a um agrupamento tradicional. Um casal e sua prole, pai, mãe e filhos não são equações estáveis o suficiente para constituírem fundamento, sustentáculo da nova comunidade. Laços sanguíneos ou um contrato civil não asseguram a harmonia em meio a dissenso, ou o comprometimento com uma ética que questiona o projeto liberal. A resposta: família por eleição, a união de "indivíduos que, apesar de suas diferenças, compartilham experiência, que escolhem eleger-se comunidade militante, comprometida com a batalha contra a doença e a implantação de políticas diferenciadas”. ${ }^{26}$ Em Angels in America: Perestroika, Belize, Louis, Hannah $^{27}$ e Prior formam um núcleo exemplar, são os arautos de uma democracia radical, de uma pátria progressista onde,

[e] sta doença será o fim de muitos, mas não de todos, e [onde] os mortos serão lembrados e lutarão ao lado dos vivos, e [onde] não iremos desaparecer. [Onde] nos recusaremos a

\footnotetext{
${ }^{24}$ KUSHNER. Angels in America, a Gay Fantasia on National Themes, p. 254-257. "You sonofabitch."

${ }^{25}$ BHABHA. Introdução a Nation and Narration, p. 57.

${ }^{26}$ CADDEN. Strange angel: The Pinklisting of Roy Cohn, p. 88. "Kushner leaves us with the image of four individuals who, despite their very real differences, have chosen, based on their collective experience, to think about themselves as a community working for change."

${ }^{27}$ Hannah é a mãe do personagem Joe Pitt. Kushner a introduz na narrativa quando Joe a contacta, em meio a uma crise de identidade sexual. Por conta disso, Hannah vai para Nova York, na expectativa de ajudar seu filho. Ironicamente, é Prior quem ela socorre, depois de alguns percalços e desentendimentos. Apesar de suas diferenças, eles forjam uma relação de afeto e se tornam grandes amigos. Ao fim da peça, Hannah compõe a família por eleição de Prior, juntamente com Louis e Belize.
} 
agonizar em segredo. $\mathrm{O}$ mundo só se move para a frente. Nós seremos cidadãos. Chegou a hora. $^{28}$

As minorias - étnicas, culturais, de gênero, sexuais - são os herdeiros legítimos dos Estados Unidos. O futuro a elas pertence; é delas a responsabilidade de narrar a nacionalidade. A mensagem final da peça, proferida por Prior, que se recusa a desempenhar o papel de profeta da estagnação, é um pronunciamento otimista, que substitui a desesperança e a frustração dos anos Reagan pela resistência e compaixão. Ele se dirige à plateia, "Vocês são fabulosos, cada um de vocês. E eu os abençôo: Mais Vida. A Grande Obra Principia", 29 abençoando-nos a todos, implicando-nos na luta, fomentando a discussão.

A peça de Kushner, pois, é arte engajada, que se quer antídoto contra a complacência. A versão final da obra, ponto de referência para as muitas montagens desde a estreia, é local privilegiado de interação entre o passado, a história, a memória e a nossa contemporaneidade. Mais que isso, é local onde se forjam alianças insuspeitadas, onde se celebra a multiplicidade de enunciados artísticos, onde se leem as cicatrizes e elabora-se a perda. Quando a assistimos (lemos), estabelecemos, por meio de seu intermédio, uma relação de continuidade com o que já foi, com aquele período durante o qual a indiferença criminosa do governo foi uma constante e o vírus da AIDS se alastrou. $\mathrm{O}$ passado remete a instantes de violência e intolerância intensas; o presente, a complicações provenientes da tragédia que não se conseguiu evitar e o futuro, a possibilidades e incertezas. Espacialidades e temporalidades coexistem, com as falas e os personagens a evocarem e invocarem a tensão entre a lembrança e o esquecimento, entre a história oficial e os pontos de vista discordantes, atravessados pela diferença.

A narrativa de Prior Walter, Roy Cohn e outros tantos infectados se insere então nesse domínio, em que a versão homogeneizante, unificadora hesita, omite e silencia. Com isso, a dramatização de eventos criada por Kushner aponta necessariamente para acontecimentos e pessoas ausentes do relato dominante, que ficaram nos vazios da história. Essa dramaturgia não é coisa única, estanque. Ela é linguagem e morte, transmutação da dor e jogo de luto, representação das vidas que se foram (e das que seguem) e monumento.

\footnotetext{
${ }^{28}$ KUSHNER. Angels in America, a Gay Fantasia on National Themes, p. 280. "This disease will be the end of many of us, but not nearly all, and the dead will be commemorated and will struggle on with the living, and we are not going away. We won't die secret deaths anymore. The world only spins forward. We will be citizens. This time has come."

${ }^{29}$ KUSHNER. Angels in America, a Gay Fantasia on National Themes, p. 280. "You are fabulous creatures, each and every one. And I bless you: More Life. The Great Work Begins."
} 


\section{A B S T R A C T}

This article analyses Angels in America, a gay fantasia on national themes, by the American dramatist Tony Kushner. In what many believe to be his major work, Kushner weaves the lives of fictional and historical characters into a web of social, political, and sexual revelations, focusing on the discovery of AIDS, the disregard with which politicians marginalized its early spread and the impact of the disease on the gay community. As it is, Kushner's work rethinks the recent past and portrays alternatives absent from the dominant reports. Moving beyond the official version of events, Angels in America is thus a counter-narrative, one where the master narrative implodes on itself, one where new stories arise out of the ashes of that explosion.

\section{KEYWORDS}

Tony Kushner, Contemporary American Theater, National narrative and counter-narrative

\section{REFERÊNCIAS}

BENJAMIN, Walter. Sobre o conceito da história. In: - Magia e técnica, arte e política. Ensaios sobre literatura e história da cultura. São Paulo: Brasiliense, 1987. (Obras escolhidas, v. 1). p. 222-232.

BHABHA, Homi K. Introdução a Nation and Narration. In: ROUANET, M. H. (Org.). Nacionalidade em questão. Rio de Janeiro: Instituto de Letras-UERJ, 1997. p. 1-59.

BREEN, T. H. A era Reagan. In: BREEN, T. H.; DIVINE, Robert A. et al. (Org.). América, passado e presente. Rio de Janeiro: Nórdica, 1992. p. 717-740.

BURKE, Peter. Abertura: a Nova História, seu passado e seu futuro. In: BURKE, Peter. (Org.). A escrita da história: novas perspectivas. São Paulo: UNESP, 1992. p. 7-37.

CADDEN, Michael. Strange Angel: The Pinklisting of Roy Cohn. In: GEIS, Deborah R.; KRUGER, Steven F. (Org.). Approaching the Millennium: Essays on Angels in America. Ann Arbor: The University of Michigan Press, 1997. p. 78-89.

CARR, E. H. Que é história. Rio de Janeiro: Paz e Terra, 1976.

HUTCHEON, Linda. Poética do pós-modernismo: história, teoria, ficção. Rio de Janeiro: Imago, 1991.

KUSHNER, Tony. Angels in America, a Gay Fantasia on National Themes. New York: Theatre Communications Group, 1995.

SHEWEY, Don. Tony Kushner's Sexy Ethics. Disponível em: < http://www.donshewey.com/ theater_articles/tony_kushner.html>. Acesso em: 30 jun. 2009.

SHILTS, Randy. O prazer com risco de vida. Rio de Janeiro: Record, 1987.

SINDER, Valter. A reinvenção do passado e a articulação de sentidos: o novo romance histórico. Estudos Históricos, Rio de Janeiro, v. 14, n. 26, p. 253-264, 2000.

SONTAG, Susan. AIDS and its Metaphors. In: . Illness as Metaphor; and AIDS and its Metaphors. New York: Farrar, Straus \& Giroux, 1989. p. 89-183. 